\title{
Aging and Human Sexual Behavior: Biocultural Perspectives - A Mini-Review
}

\author{
Peter B. Gray ${ }^{a} \quad$ Justin R. Garciab \\ ${ }^{a}$ Department of Anthropology, University of Nevada, Las Vegas, Nev., and ${ }^{\mathrm{b}}$ The Kinsey Institute for Research in Sex, \\ Gender, and Reproduction, Indiana University, Bloomington, Ind., USA
}

\section{Key Words}

Senescence $\cdot$ Evolution $\cdot$ Life history $\cdot$ Sexual behavior $\cdot$

Sexuality $\cdot$ Sexual function $\cdot$ Menopause

\begin{abstract}
In this mini-review, we consider an evolutionary biocultural perspective on human aging and sexuality. An evolutionary approach to senescence highlights the energetic trade-offs between fertility and mortality. By comparing humans to other primates, we situate human senescence as an evolutionary process, with shifts in postreproductive sexual behavior in this light. Age-related declines in sexual behavior are typical for humans but also highly contingent on the sociocultural context within which aging individuals express their sexuality. We briefly review some of the most comprehensive studies of aging and sexual behavior, both from the USA and cross-culturally. We frame these patterns with respect to the long-term relationships within which human sexual behavior typically occurs. Because sexuality is typically expressed within pair-bonds, sexual behavior sometimes declines in both members of a couple with age, but also exhibits sex-specific effects that have their roots in evolved sex differences.

Copyright $\odot 2012$ S. Karger AG, Basel
\end{abstract}

'Frequency of sex over age 45 was not calculated because most of the older women were single due to the loss of their husband, divorced or stopped having sex with their husbands. There is general belief and practice that when one's own children start to have children of their own it is time to reduce sexual activity to help with the grandchildren and make sure existing dependent children survive.'

Barry Hewlett and Bonnie Hewlett [1], describing features of aging and sexuality among Aka foragers of the Central African Republic.

In this mini-review, we consider an evolutionary biocultural perspective on aging and sexuality, highlighting some of the most comprehensive studies of aging and sexual behavior, both from the USA and internationally. We find that age-related declines in human sexual behavior are typical but also highly contingent on the sociocultural context within which aging individuals express their sexuality, as the above quote describing the Aka illustrates. Because both men and women typically express their sexuality within long-term relationships, their sexual behavior sometimes changes in tandem (i.e. declines in both members of a couple with age), but can also exhibit sex-specific effects that have their roots in evolved sex differences.

\section{KARGER}

Fax +41613061234

E-Mail karger@karger.ch

www.karger.com
(C) 2012 S. Karger AG, Basel

0304-324X/12/0585-0446\$38.00/0

Accessible online at:

www.karger.com/ger
Peter B. Gray, Associate Professor

Department of Anthropology, University of Nevada

4505 Maryland Parkway, Box 455003

Las Vegas, NV 89154-5003 (USA)

Tel. +1 702895 3586, E-Mail peter.gray@unlv.edu 


\section{Senescence}

An evolutionary perspective on aging recognizes that species should invest in maintenance functions (such as immune systems in mammals) if age-specific fertility and mortality pay to do so. If, for example, members of a species continue to reproduce and are subject to sufficiently low extrinsic mortality (mortality that is difficult to avoid, such as predation), then they can afford to maintain themselves, investing in their own capacities for continued survival, and in turn living long lives. There is empirical cross-species support for this body of theory. To illustrate, let us contrast mainland opossums living in the south of the USA with opossums living on a nearby island, where they had been isolated from predators for thousands of years. Austad [2] predicted and found support for the hypothesis that the island opossums would senesce at slower rates than their mainland cousins. Under the idea that islanders faced lower extrinsic mortality due to lower rates of predation, he found that island opossums died at slower rates with advancing age (meaning the average islander lived a longer life) and also scored lower on a physiological measure of stress (wear and tear to their tail tendon fibers). As other examples, bats tend to outlive their similarly sized mammalian cousins such as squirrels, a pattern consistent with theory since bats can more readily escape would-be predators by flying away, enabling them to invest in maintenance functions [2]. Tortoises, like those Charles Darwin encountered in the Galapagos Islands, tend to lead long lives, in part because they hold protection (hard shells) literally on their backs. Such examples illustrate how fertility and mortality schedules shape the rate of senescence (loss of function with age) among organisms.

The disposable soma theory articulates an evolutionary perspective on aging, by considering the life history trade-offs involved with maintenance. These trade-offs ultimately impact reproductive function, not as a result of population control (as some have argued), but as a result of natural energetic concessions [3]. The disposable soma theory proposes that 'ageing results principally from limited evolutionary pressure to invest in mechanisms of somatic maintenance and repair... it is only necessary to maintain somatic cells and tissues to a standard that will prevent premature decline... Once an organism reaches an age when survivorship in the wild is highly unlikely, the state of its somatic integrity, or otherwise, is inconsequential. Since, other things being equal, unnecessary investment in better somatic maintenance than is actually required will be to the detriment of either growth, or reproduction or other fitness-enhancing functions, the evolutionarily optimal investment in maintenance should be insufficient to secure somatic immortality, and ageing should occur through the gradual accumulation of unrepaired molecular and cellular damage' [3, p. R703].

\section{Evolution of Human Aging}

What light does this evolutionary perspective shed on human aging? Humans senesce at slower rates than our great ape cousins, and apes, in turn, senesce at slower rates compared with other primates such as lemurs and both old-world monkeys (e.g. rhesus) and new-world monkeys (e.g. squirrels). As an example, wild chimpanzee mortality data from five field sites in Africa showed that almost every chimpanzee was dead by age 50 [4]. By contrast, recent studies of human hunter-gatherers and horticulturalists such as the !Kung of the Kalahari, the Hadza of Tanzania, the Ache of Paraguay and the Tsimane of Bolivia have found that these human populations have longer lives than our ape cousins living either in captivity or the wild [5]. Of course, recent human hunter-gatherers also have technological and cognitive shields (controlled use of fire, projectile weapons, knowledgeable elders) against environmental insults that our more distant foraging ancestors lacked. How far back, then, we can project mortality patterns from recent foragers to more distant foragers is an open question. The available bioarchaeological samples (e.g. estimating age profiles of past hominin species) contain few old individuals, although older individuals became more common more recently in the genus Homo. When combining this line of evidence with other paleoanthropological data on rates of development, brain size estimates and archaeological evidence of tool use and subsistence, along with the comparative ape and contemporary hunter-gatherer data, the best guess would be that the slower rate of human senescence evolved in the genus Homo at some point within the past 2 million years [6]. A more specific educated guess would be that only with modern humans ourselves within the past 200,000 or so years have people been living long enough to even contemplate a postreproductive existence [7].

Considerable debate has arisen concerning why human females, in particular, live well beyond their reproductive capacities [8-10]. The current formulations of the 'grandmother hypothesis' recognize that human female reproductive senescence is virtually identical to that of chimpanzees (e.g. rates of follicular atresia are remark- 
ably similar between chimpanzees and humans of similar age [11]). An extended life span gives rise to postreproductive female existence. While some argue that the cause of extended human life spans is grandmaternal care (i.e. a postreproductive female caring for her grandoffspring, generating indirect fitness benefits favoring her continued survival), others view grandparenting as a byproduct of life spans that have been extended for other reasons, and still others point out that patterns of grandmaternal investment may depend on the sex of the grandoffspring [12]. Several arguments favor the latter byproduct view, focusing on the fact that selection tends to be relatively weak or absent for any traits specific to postreproductive years of life.

The comparative nonhuman evidence convincingly demonstrates that postreproductive female lives are hardly unique to humans. However, even among forager groups, humans appear to spend a significantly longer proportion of their lives in postreproductive states than is the case in postreproductive captive animals. Among older gorilla females living in US zoos, 5 of 22 had ceased menstrual cycling altogether (were postmenopausal, in other words) and another $32 \%$ of older females displayed irregular menstrual cycles akin to a perimenopausal woman [13]. Interestingly, peri- and postmenopausal gorillas no longer maintained the same social affiliations with a silverback (adult male gorilla), though whether that is because females were not interested in doing so or males were not as interested in the females, or both, we do not know [13]. As Finch and Holmes [14] put it, after reviewing the evidence in many captive mammalian groups, from mice to opossums to golden lion tamarins, '[A] gradual pattern of female reproductive aging, with substantial postreproductive periods consistent with expectations for mammals with fixed oocyte pools, appears to be a conservative mammalian trait...' (p. 89). Put another way, the overall theoretical and empirical evidence is most consistent with the view that human senescence has a number of parallels with captive nonhuman animals and has slowed recently in hominin evolution (perhaps only with modern humans ourselves). This has given rise to common and extended postreproductive lives that can be spent having sex, among other things.

While most of the focus on human reproductive aging has centered on females, male senescence can also be understood in an evolutionary perspective $[15,16]$. Estimates of age-specific fertility in forager societies such as the !Kung, Hadza, Agta and Ache suggest that male agespecific fertility has a similar shape to that of females in all of these populations, in large part because most hu- man reproduction occurs within long-term bonds, thus intertwining a couple's fertility [17]. The fact that human sexual and reproductive behavior typically occurs within long-term (slightly polygynous) bonds is noteworthy, as this social context differs from our great ape cousins and was likely derived within the past 2 million years of Homo evolution $[16,18]$. Still, male age-specific fertility is shifted toward slightly older ages than females' in these same populations, in part because males tend to be older at marriage (and thus older at the time of fertilization) and may be more likely to reproduce after separation or divorce. Yet, male reproductive potential does decline with age, with age-specific fertility quite low by the 50 s and onwards. In a prospective fecundability study of $782 \mathrm{cou}-$ ples (women aged 18-40 years), both men and women experienced increased infertility with age [19]. Humans, like most other species of mammals, also exhibit sex differences in senescence, which ultimately can be traced to sexual selection. Across various studies of mammals and birds in the wild, polygynous species typically display sex differences in mortality (males having shorter lives, on average), whereas among monogamous species, male and female mortality profiles are similar [20]. Human males tend to live shorter lives on average than females, although at lessened intensity compared with, say, orangutans or gorillas.

\section{Aging and Sexuality}

An evolutionary perspective on senescence helps make sense of age-related changes in the proximate mechanisms regulating sexual response [21, 22]. For both females and males, general frailty declines at slower rates than our closest primate cousins, making it easier for older humans to remain sexually active (they are alive, and better able to function, though subject to the influence of declining health). Female peak fecundity occurs at ages 25-35, declines toward menopause and ceases altogether at menopause. With advancing age, the ovary reduces its capacity to both produce a fertilizable egg and release sex steroids that facilitate sexual response. Age-related declines in estrogen, especially during the menopausal transition, negatively impact vaginal lubrication, elasticity and vasocongestion and can also reduce sexual desire. Estrogen-related declines in oxytocin function might also have an impact on a woman's emotional investment in an ongoing sociosexual relationship. Male reproductive function reveals declines in testosterone by the early 30 s onwards, although there is also population variation 


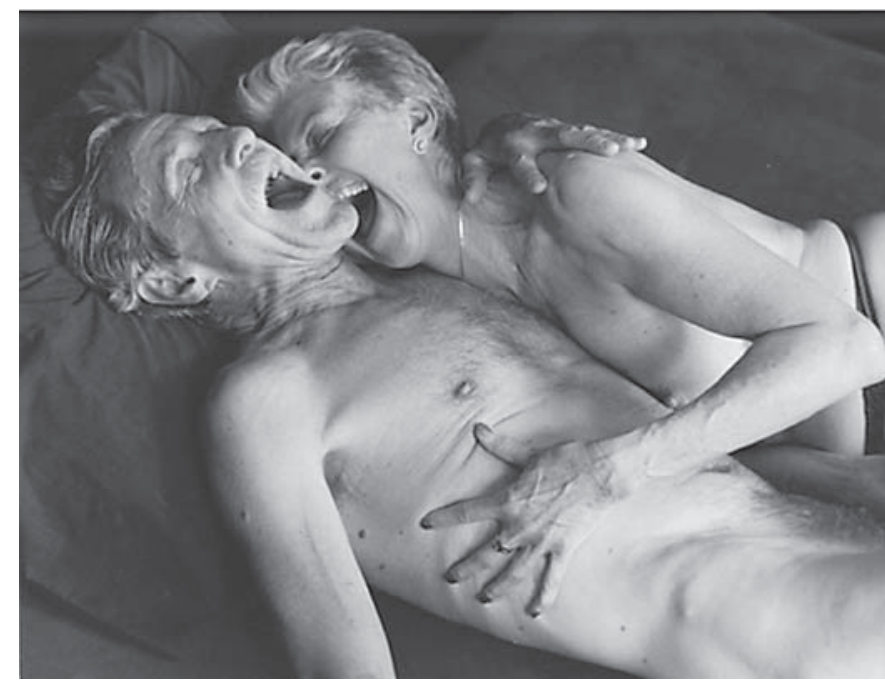

Fig. 1. Photograph from the Juliet-Victor series by David Steinberg (www.davidsteinberg.us). Cropped and reprinted, with permission, from David Steinberg. Courtesy of The Kinsey Institute for Research in Sex, Gender, and Reproduction.

in the pattern of decline. Male declines in sexual desire and erectile function are more pronounced from the $60 \mathrm{~s}$ onwards and may, in part, be traced to age-related declines in testosterone. All said, the mechanisms of female and male sexual function decline with age, patterns that can be understood with respect to the evolutionary background highlighted above and that would anticipate agerelated changes in actual sexual behavior. These age-related changes in reproductive physiology also point to age-related shifts in aggression, courtship and childcare (e.g. postmenopausal women shifting their behavioral efforts toward greater investment in descendant kin vs. seeking new mates), though these are largely outside the scope of this current review.

In parts of India, a couple is supposed to stop engaging in sex once their eldest son marries, a sexual recognition of shifting family priorities. In the 19th century Oneida commune of upstate New York, young men were sexually kept by postmenopausal women. The 'complex marriages' practiced by the Oneida religious commune allowed for orchestrated sexual activity as well as strategic partnerships. The age-stratified pairings of postmenopausal women with young men avoided pregnancies but also occupied the young men so that (older) male political leaders could have less encumbered sexual access to the group's young women. Among !Kung women of southern Africa, 'An older woman may take a younger man as a lover and do this more openly....There seems to be less danger attached to it, since husbands are often away for long periods or perhaps are less jealous.' [23, p. 41]. In light of these anecdotes, what about broader patterns of sexual behavior associated with human aging? (fig. 1). Here, we present the results of several large, recent quantitative US studies, before also considering patterns drawn from several international studies.

\section{Aging and Sexual Behavior in the USA}

In the USA, the frequency of sexual intercourse over a 1 -year period was found to be inversely related to age, with those 18-30 years reportedly averaging sex 78 times per year, compared to those 60-69 years averaging 23 times per year [24]. More recently, in 2007, Lindau et al. [25] conducted a nationally representative US survey of sexual behavior that was based on interviews with around 3,000 adults aged $57-84$. By asking whether an individual had sex in the previous 12 months, it was found that the proportion of men and women sexually active declined with age but was lower at all ages among women. More specifically, $84 \%$ of men aged 57-64 reported sexual activity in the past 12 months, compared with $67 \%$ among 65-74 year olds and 39\% among 75-84 year olds. Among women, 62\% among those aged 57-64, 40\% among those aged $65-74$ and $17 \%$ among those aged $75-$ 84 reported sexual activity in the previous 12 months. Thus, the falloff in sex with advancing age is a robust feature.

As for sexual practices, the vast majority entails vaginal intercourse. For example, $87 \%$ of women aged $57-64$ and $91 \%$ of men aged 57-64 report usually having vaginal intercourse. Of other sexual practices, rates of both oral sex and masturbation drop off steeply with advancing age. With regard to oral sex, 53\% of women aged 5764 reported engaging in this activity in the previous 12 months, whereas $35 \%$ of 75 - to 84 -year-old women reported this; for males, the parallel report rates were $62 \%$ among participants aged 57-64 and 28\% among those aged 75-84. With regard to masturbation, these rates drop from $32 \%$ of women reporting this in the previous 12 months among 57-64 year olds to $22 \%$ among 65-74 year olds to $16 \%$ among women aged $75-84$. Parallel rates in men are $63 \%$ of $57-64$ year olds, $53 \%$ of $65-74$ year olds and $28 \%$ of $75-84$ year olds [25]. The drop in masturbation, which does not require the same negotiations with a partner as oral sex or intercourse, suggests that other factors such as declining sexual desire are 
wielding measurable effects on age-related changes in sexual behavior. It is worth noting that fairly recent historical shifts in sexual culture, including the hierarchical reordering of oral sex and intercourse [26], may also result in a cohort effect with respect to rates of specific sexual behavior.

How should we interpret the sex differences in agerelated patterns of sexuality? One view is that these may be indicative of sex differences in sexual desire that persist at advancing ages; that interpretation could be most sensible with respect to sex differences in masturbation. However, another major cause of these patterns is that the demographic landscape changes with advancing age; with men often older than their sexual partners, men dying at younger ages and women less likely to remarry, the demographics at older ages increasingly tilt toward living females. The consequence is that 'The impact of age on the availability of a spouse or other intimate partner is particularly marked among women. A total of $78 \%$ of men 75-84 years of age, as compared with $40 \%$ of women in this age group, reported having a spousal or other intimate relationship.' [25, p. 772]. Since most sex occurs within long-term relationships such as marriage, older women simply have fewer sexual options available to them. Poor self-reported health was also associated with lower rates of sexual behavior, in females and males alike. In addition to age-related health problems that may impact sexual activity, a variety of medications taken for age-related conditions have side effects of reducing sexual desire and performance.

An even more recent US survey in 2010 (National Survey of Sexual Health and Behavior) yielded generally similar patterns of age-related changes in sexual behavior, although relying on a wider age spread (participants 1494 years of age) and different methods (e.g. data collection over the Internet rather than interviews) [27]. As an example, during the previous 12 months, $51 \%$ of women aged $50-59,42 \%$ of women aged $60-69$ and $22 \%$ of women aged 70 and older reported having engaged in vaginal intercourse, whereas among men of these same age groups, $58 \%, 54 \%$ and $43 \%$, respectively, reported engaging in vaginal intercourse in the past year. Further, 54\% of women aged 50-59, 47\% of women aged 60-69 and $33 \%$ of women aged $70-79$ reported masturbating alone during the past 12 months, with comparable rates among men of $72 \%, 61 \%$ and $46 \%$. This survey also presented data on other time frames (the past month, during one's life) and for a greater variety of categories of sexual behavior (e.g. distinguishing performing from receiving oral sex). The age-related declines and lower rates of sex- ual behaviors among females appeared in this study as in the earlier one. Also of note, among men aged 50-59 years and older, a higher percentage reported performing and receiving oral sex from another male compared with the rates of females performing and receiving oral sex from another female, an indication that in advanced ages the rates of same-sex male sexual behavior were higher than the rates of same-sex female sexual behavior.

One of the best studied aspects of aging and human sexuality has been across the menopausal transition. While aging itself may influence sexuality, a related question has concerned effects specifically traced to the physiological effects of menopause itself. Reviewing approximately 15 studies, with both cross-sectional and longitudinal designs, Dennerstein et al. [28] found that the best of these (e.g. longer duration, measuring hormones) consistently documented an influence of the menopausal transition on measures of sexuality such as elevated dyspareunia (pain during intercourse) and reduced sexual desire, with effects linked to declining estrogen. As a gold standard of US longitudinal studies of this type, involving over 3,000 women aged 42-52, the Study of Women's Health Across the Nation observed similar effects of the menopausal transition on dyspareunia and sexual desire, but without effects on intercourse frequency.

\section{Aging and Sexual Behavior Cross-Culturally}

Providing an international view of aging and sexuality, Laumann et al. [29] investigated sexual attitudes and behavior in 29 countries, including South Africa, Japan, Australia and Mexico, surveying 27,500 sexually active men and women aged 40-80. The data were presented differently, not allowing direct comparisons with the US data by age or sex with regard to rates of sexual behavior, as the focus was on clustering the global patterns of aging and sexuality by attitudinal and relationship factors. As a central finding, there was a positive relationship across countries in the percentage of participants who reported satisfaction with their sexual function and relationship satisfaction. At the low end, around $60 \%$ of Japanese and Taiwanese reported satisfaction with sexual function, with around $15 \%$ of Japanese and $20 \%$ of Taiwanese reporting relationship satisfaction. At the high end, approximately $90 \%$ of Australians reported satisfaction with sexual function and around $70 \%$ relationship satisfaction. Important messages, then, from this international study are that sexual satisfaction and relationship satisfaction are highly related (no surprise given the prima- 
cy of long-term relationships in human sexuality) and that considerable variation in sexual and relationship satisfaction exists among aged populations.

Another important finding from this international study [29] concerns sex differences in reported sexual well-being. Men reported higher levels of physical pleasure, emotional pleasure, satisfaction with sexual function and importance of sex than did women. However, the magnitude of these sex differences varied by 'clusters' (in which cluster 1 consisted of countries such as Australia, with high sexual and relationship satisfaction, and cluster 3 consisted of countries such as Japan and Taiwan, with relatively low rates of both). In this vein, the findings 'support the notion that the ideal of companionate relationships tends to value positively sexual competencies, interests, and performance between intimate sex partners. In other words, sex in companionate relationships serves not only reproductive purposes, but also expresses the quality of the relationship.' [29, p. 158].

In an attempt to systematically investigate aging and sexuality in a sample of small-scale societies of huntergatherers, agriculturalists, pastoralists and the like, Winn and Newton [30] utilized the Human Relations Area Files for data referring to older men and women's sexuality. They found that older males were sexually active in 20 of 28 societies, and older females were sexually active in 22 of 26 societies from which they could obtain data. Thus, the admittedly slim Human Relations Area Files data indicate that older women and men are quite commonly sexually active with advancing age.

One means by which older men remain sexually active in some societies is by marrying younger wives, sometimes in polygynous unions. The desire to have more children is sometimes articulated as a reason for older men remaining sexually active with their younger wives, as among Kuwaiti Bedouin and the Chukchee. However, a refrain in at least five societies, including among prospective young brides in the Trobriands and among the Lovedu of South Africa, is that old men are not physically attractive. In some other cases, such as the Taiwan Hokkien, the thought that older men and women remain sexually active is found distasteful, but for a different reason, namely that they already have grandchildren. Here, it is expected that grandparents will sacrifice their sex lives to focus on raising their grandchildren.

One of the noteworthy patterns of female sexuality is that reports from 18 of 22 societies indicated that women had sex with younger men, sometimes considerably younger. In some cases, it appears that their younger male partners were desirable, with some of them married men.
However, in the majority of cases this seems to reflect a context in which older women are not viewed as most desirable, but rather taken as partners because they are the only ones available to some men. As Winn and Newton [30] put it, 'Older women were resorted to as sexual partners only by young men who were able to find no other outlets, as in the case of the Marquesa Islanders of French Polynesia, the aboriginal Easter Islanders, the Inca of Peru, the Nambicuarar of Brazil, and the Trumai of Mato Grosso. Older women were also utilized by young boys as sexual initiators and sexual instructors in several of the societies reported, as in the Tupinamba of northeast Brazil...' (p. 293). Given marital customs whereby a young husband might marry a much older woman (e.g. in levirate marriage, when he 'inherits' her as a spouse after an older husband dies), he might find himself sexually active with a considerably older wife.

Another noteworthy pattern in female sexuality was that older women frequently experienced a loosening of constraints to their sexual expression. With their reproductive capacities past, older women might make ribald jokes and display an enhanced sexual aggressiveness, as among the Taiwanese Hokkien and the Muria of India. According to Winn and Newton [30], 'These behaviors included exposure of the genitals, suggestive dancing, imitation of copulatory movements in public, clutching the genitals of men in public, and requesting sexual intercourse from strangers' (p. 295). Older women, then, are subject to fewer constraints and inhibitions. It is also worth highlighting that men do not appear to undergo this same degree of expanded latitude with age. Aging women also tend to avoid outlets for their sexuality; among the Tallensi of Ghana and Kanuri of Nigeria, older women might shun or be shunned by an aged husband, moving in with an adult son instead.

\section{Conclusion}

Across these studies of aging and sexual behavior, several patterns stand out. One is that the frequency and diversity of sexual behavior tends to decline with age, which is consistent with expectations of evolutionary theory and age-related changes in mechanisms of sexual response. Another pattern is that sexual behavior is typically expressed within long-term partnerships, marking the importance of these from a recently derived evolutionary standpoint, but also with regard to demographic and cultural aspects of partner availability [18]. Finally, the specifics of aging and sexual behavior are clearly 
highly socially contextualized, highlighting the importance of research that combines evolutionary, mechanistic and social accounts to best make sense of age-related patterns in human sexual behavior.

\section{Acknowledgement}

J.R.G. is supported in part by National Institutes of Health NICHD grant T32HD049336.

\section{References}

1 Hewlett BS, Hewlett BL: Sex and searching for children among Aka foragers and Ngandu farmers of central Africa. Afr Study Monogr 2010;31:107-125.

2 Austad SN: Why We Age. Hoboken, Wiley, 1999.

3 Kirkwood TBL, Melov S: On the programmed/non-programmed nature of ageing within the life history. Curr Biol 2011; 18:R701-R707.

4 Hill K, Boesch C, Goodall J, Pusey A, Williams J, Wrangham R: Mortality rates among wild chimpanzees. J Hum Evol 2001;40:437450.

5 Gurven M, Kaplan H: Hunter-gatherer longevity: cross-cultural perspectives. Popul Dev Rev 2007;33:321-365.

6 Lieberman DE: The Evolution of the Human Head. Cambridge, Belknap Press of Harvard University Press, 2011.

7 Crews DE, Stewart JA: Human longevity and senescence; in Muehlenbein M (ed): Human Evolutionary Biology. New York, Cambridge University Press, 2010, pp 528-550.

$>8$ Hawkes KJ, O'Connell F, Blurton Jones NG, Charnov EL, Alvarez H: Grandmothering, menopause, and the evolution of human life histories. Proc Natl Acad Sci USA 1998;95: 1336-1339.

9 Voland E, Chasiotis A, Schiefenhövel W (eds): The Evolutionary Significance of the Second Half of Female Life. Piscataway, Rutgers University Press, 2005.

$>10$ Lachmann PJ: The grandmother effect. Gerontology 2011;57:375-377.

-11 Jones KP, Walker LC, Anderson D, Lecreuse A, Robson SL, Hawkes K: Depletion of follicles with age in chimpanzees: similarities to humans. Biol Reprod 2007;77:247-251.
12 Johow J, Fox M, Knapp LA, Voland E: The presence of paternal grandmother lengthens interbirth interval following the birth of a granddaughter in Krummhorn (18th and 19th centuries). Evol Hum Behav 2011;32: 315-325.

13 Margulis SW, Atsalis S, Bellem A, Wielebrowski N: Assessment of reproductive behavior and hormonal cycles in geriatric western Lowland gorillas. Zoo Biol 2007;26:117139.

14 Finch CE, Holmes DJ: Ovarian aging in developmental and evolutionary contexts. Ann NY Acad Sci 2010;1204:82-94.

15 Bribiescas RG: Men: Evolutionary and Life History. Cambridge, Harvard University Press, 2006.

16 Gray PB, Anderson KG: Fatherhood: Evolution and Human Paternal Behavior. Cambridge, Harvard University Press, 2010.

17 Tuljapurkar SD, Puleston CO, Gurven MD: Why men matter: mating patterns drive evolution of human lifespan. PLoS One 2007; 2:e785.

18 Gray PB, Garcia JR: Darwin's Bedroom: Evolution and Human Sexual Behavior. Cambridge, Harvard University Press, under review.

19 Dunson DB, Baird DD, Colombo B: Increased infertility with age in men and women. Obstet Gynecol 2004;103:51-56.

20 Clutton-Brock TH, Isvaran K: Sex differences in ageing in natural populations of vertebrates. Proc Biol Sci 2007;274:3097-3104.

21 Knobil E, Neill JD: Knobil and Neill's Physiology of Reproduction, ed 3. New York, Academic Press, 2006.
22 Masters WH, Johnson VE: Human Sexual Response. Boston, Little, Brown and Company, 1966.

23 Lee RB: Work, sexuality, and aging among !Kung women; in Kerns V, Brown JK (eds): In Her Prime: New Views of Middle-Aged Women, ed 2. Urbana and Chicago, University of Illinois Press, 1992, pp 35-48.

24 Seidman SN, Rieder RO: A review of sexual behavior in the United States. Am J Psychiatry 1994;151:330-341.

25 Lindau ST, Schumm LP, Laumann EO, Levinson W, O’Muircheartaigh, Waite LJ: A study of sexuality and health among older adults in the United States. N Engl J Med 2007;357:762-774.

26 Garcia JR, Reiber C, Massey SG, Merriwether AM: Sexual hook up culture: a review. Rev Gen Psychol 2012, in press

27 Herbenick D, Reece M, Sanders SA, Schick V, Dodge B, Fortenberry JD: Sexual behavior in the United States: results from a national probability sample of males and females ages 14-94. J Sex Med 2010;7(suppl 5):255-265.

28 Dennerstein L, Alexander JL, Kotz K: The menopause and sexual functioning: a review of the population-based studies. Annu Rev Sex Res 2003;14:64-82.

29 Laumann EO, Paik A, Glasser DB, Kang J-H, Wang T, Levinson B, Moreira ED, Nicolosi A, Gingell C: A cross-national study of subjective sexual well-being among older women and men: findings from the global study of sexual attitudes and behaviors. Arch Sex Behav 2006;35:145-161.

30 Winn RL, Newton N: Sexuality in aging: a study of 106 cultures. Arch Sex Behav 1982; 11:283-298. 